\title{
Influence of supplementation with different oenological tannins on malvidin-3-monoglucoside copigmentation
}

\author{
Jordi Gombau $^{1}$, Adeline Vignault ${ }^{2}$, Olga Pascual ${ }^{1}$, Joan Miquel Canals ${ }^{1}$, Pierre-Louis Teissedre ${ }^{2}$, and Fernando Zamora ${ }^{1}$ \\ ${ }^{1}$ Departament de Bioquímica i Biotecnologia, Facultat d'Enologia de Tarragona, Universitat Rovira i Virgili, C/Marcel.li Domingo, s/n \\ 43007 Tarragona, Spain \\ ${ }^{2}$ Unité de recherche Oenologie. Institut des Sciences de la Vigne et du Vin. Université de Bordeaux. 210, chemin de Leysotte. CS \\ 50008, 33882 Villenave d'Ornon Cedex, France
}

\begin{abstract}
The effect as copigment of (-)-epicatechin and five different oenological tannins has been measured in a model wine solution containing malvidine-3-monoglucoside. The results show that all oenological tannins exert a positive effect on the color of the malvidine solution, increasing the global absorptivity spectrum and changing the Cielab coordinates. Specifically, supplementation with oenological tannins increase $\mathrm{a}^{*}$ and $\mathrm{b}^{*}$ and decreases $\mathrm{L}^{*}$. Overall, the effect as copigments of all oenological tannins was higher than that of (-)epicatechin.
\end{abstract}

\section{Introduction}

The use of oenological tannins is nowadays a very common practice in winemaking, not only as a technological aid for wine clarification but also for many other aims. However, the use of oenological tannins is only authorized by the OIV to facilitate the clarification of wines and musts [1]. Nevertheless, it is unquestionable that oenological tannins are also currently used for many other purposes.

In fact, the literature has attributed to oenological tannins several other features such as antioxidant activity (protection of wines against oxidation) [2], direct consumption of dissolved oxygen [3], ability to scavenge peroxyl radicals [4], ability for chelating iron (II), preventing the oxidative damage mediated by Fentonbased reactions [5], antioxidasic activity (anti-laccase activity) [6], improvement of structure and mouthfeel of wines [7], color improvement and stabilization of red wines [8], copigmentation effect [9], direct formation of new pigments [10], elimination of reduction odors [7] and even bacteriostatic effects [11].

Among them it can be mainly highlight the following: protection of grape juice or wine against oxidation, improvement of structure and mouthfeel of wines, and specially the improvement of color intensity and stability.

With the aim of verifying the effectiveness of the different types of oenological tannins on some of their attributed functions a study about the influence on copigmentation of malvidin-3-monoglucoside has been performed.

\section{Materials and methods}

A model wine solution (ethanol 13\%; tartaric acid $4 \mathrm{~g} / \mathrm{l}$; $\mathrm{pH} 3.5$ ) containing $50 \mathrm{mg} / \mathrm{l}$ of malvidin-3-monoglucoside/l was prepared. This solution was also supplemented with $0.1,0.2$ and $0.4 \mathrm{~g} / \mathrm{l}$ of five different commercial tannins: Ellagitannins from oak, Gallotannins from gallnuts and

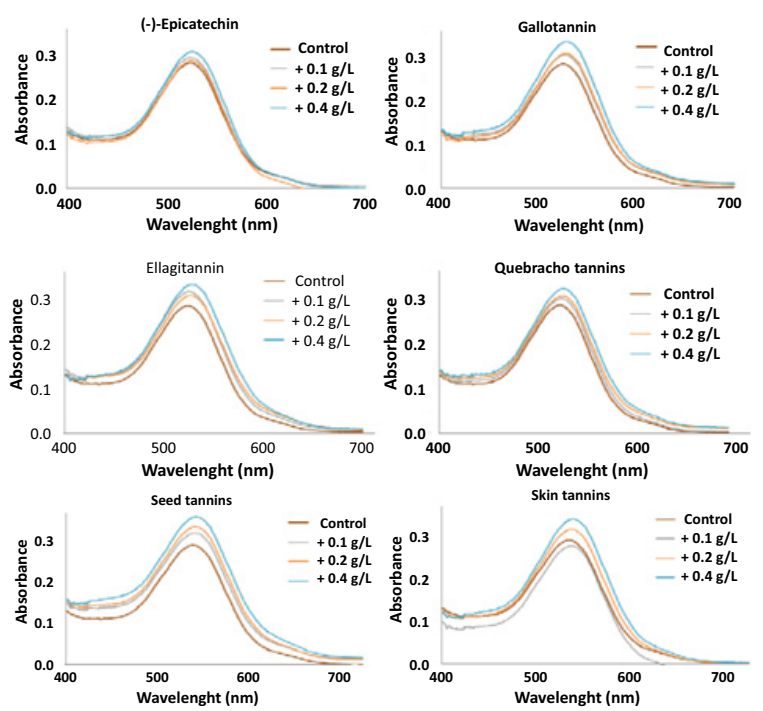

Figure 1. Influence of the supplementation of (-)-epicatechin and five different oenological tannins on the absorptivity spectrum.

condensed tannins (proanthocyanidins) from quebracho, grape seeds and grape skins. This solution was also supplemented with (-)-epicatechin to compare the obtained copigmentation effect with previously published data.

The control solution and the tannin supplemented solutions were maintained in airtight conditions (closed Eppendorf). A week later, the full absorbance spectrum in the visible range $(400-800 \mathrm{~nm})$ was measured in order to determine the CIELAB coordinates [12].

\section{Results and discussion}

Figure1 shows the absorptivity spectrum of the malvidine solution with and without supplementation with oenological tannins.

(C) The Authors, published by EDP Sciences. This is an Open Access article distributed under the terms of the Creative Commons Attribution License 4.0 (http://creativecommons.org/licenses/by/4.0/). 


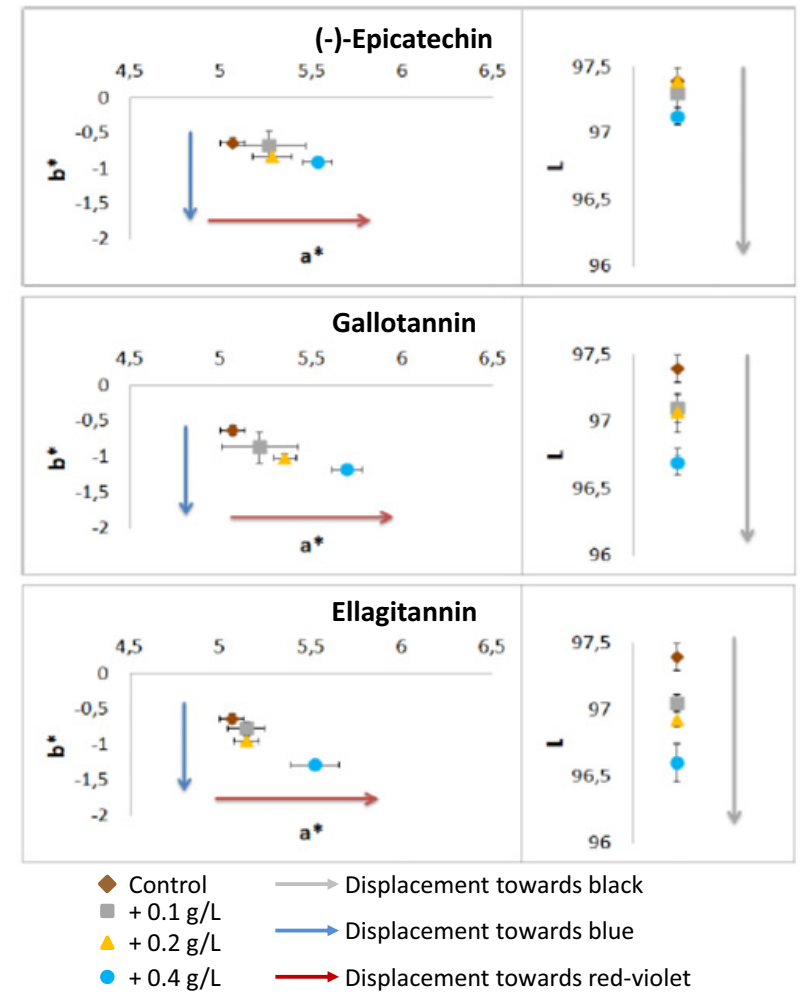

Figure 2A. Influence of the supplementation of (-)-epicatechin and hydrolysable tannins, gallotannins and ellagitannins, on the Cielab coordinates.

The results are very clear and confirm that (-)epicatechin and all the oenological tannins originated an increase in the color of the malvidine solution and that increase was in all the visible rang spectrum.

Cielab coordinates were determined to better parametrize which is the real effect of the different oenological tannins as copigments. Figures $2 \mathrm{~A}$ and $2 \mathrm{~B}$ show the obtained results. Overall the results indicate that all oenological tannins have a clear positive effect on the color inasmuch as their supplementation to a malvidine solution originates an increase in $\mathrm{a}^{*}$ (green-red component) and $\mathrm{b}^{*}$ (blue-yellow) Cielab coordinates and a decrease in L* (Lightness). In general, the enhancing effect on color of all oenological tannins was higher than that exerted by (-)epicatechin.

It can be concluded that supplementation with oenological tannins can really improve the color of red wines because of their effect as copigments. Further studies are needed to determine the long term effect of oenological tannin supplementation in real wine conditions.

We would like to thank CICYT (Projects AGL2014-56594-C21-R and AGL2014-56594-C2-2-R) for its financial support.

\section{References}

[1] International Oenological Codex-INS $\mathrm{N}^{\circ} 181$. http://www.oiv.int/public/medias/4093/ e-coei-1-tanins.pdf

[2] Hagerman, A. E., Riedl, K. M., Jones, G. A., Sovik, K. N., Ritchard, N. T., Hartzfield, P. W., \& Riechel, T. L. (1998). High molecular weight plant

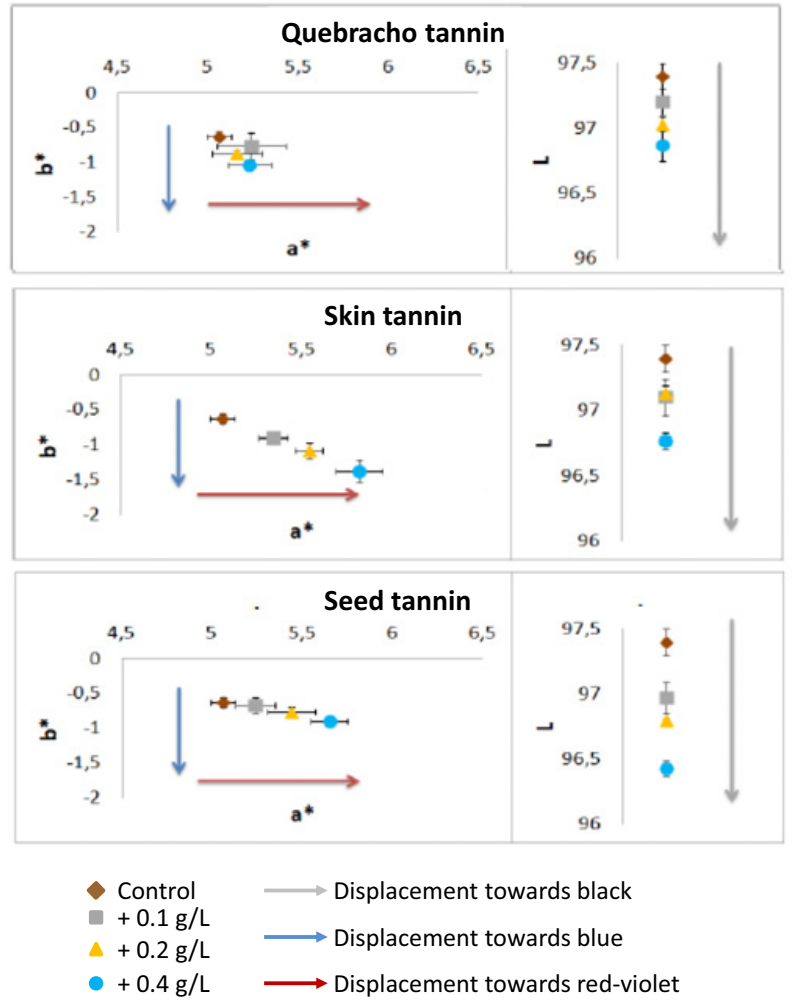

Figure 2B. Influence of the supplementation with condensed tannins, quebracho tannins, skin tannins and seed tannins, on the Cielab coordinates.

polyphenolics (tannins) as biological antioxidants. $J$. Agric. Food Chem., 46, 1887-1892

[3] Navarro, M., Kontoudakis, N., Giordanengo, T., Gómez-Alonso, S., García-Romero, E., Fort, F., Canals, J.M., Hermosín-Gutíerrez, I., Zamora, F. (2016) Oxygen consumption by oak chips in a model wine solution; Influence of the botanical origin, toast level and ellagitannin content. Food Chem., 199, 822-827

[4] Magalhães, L.M., Ramos, I.I., Reis, S., Segundo, M.A. (2014) Antioxidant profile of commercial oenological tannins determined by multiple chemical assays. Aust. J. Grape Wine Res., 20, 72-79

[5] Pérez, C.A., Wei, Y.B. and Guo, M.L. (2009) Ironbinding and anti-Fenton properties of baicalein and baicalin. J. Inorganic Biochem., 103, 326-332

[6] Obradovic, D., Schulz, M., Oatey, M. (2005) Addition of natural tannins to enhance the quality of red wine. Aust. NZ. Grapegrow. Winemaker., 493, 52-54

[7] Vivas, N. (2001) Les tanins oenologiques, d'hier à ajourd'hui: une révolution discrète que nous devons assimiler dans les pratiques de chais. Rev. Enol., 98, $11-14$

[8] Canuti, V., Puccioni, S., Giovani, G., Salmi, M., Rosi, I., Bertuccioli, M. (2012) Effect of oenotannin addition on the composition of sangiovese wines from grapes with different characteristics. Am. J. Enol. Vitic., 63, 220-231

[9] Neves, A.C., Spranger, M.I., Zhao, Y., Leandro, M.C., Sun, B. (2010) Effect of Addition of Commercial Grape Seed Tannins on Phenolic Composition, Chromatic Characteristics, and 
Antioxidant Activity of Red Wine. J. Agric. Food Chem., 58, 11775-11782

[10] Versari, A., du Toit, W., Parpinello, G.P. (2013) Oenological tannins: a review. Aust. J. Grape Wine Res., 19, 1-10

[11] Lempereur, V., Blayteyron, L., Labarbe, B., Saucier, C., Klebek, H. et Glories, Y. (2002) Groupes
National de travail sur les tanins œnologiques: premiers résultats. Rev. Fran. Enol., 196, 23-29

[12] Ayala, F., Echávarri, J.F. and Negueruela, A.I. (1997) A new simplified method for measuring the color of wines. I. Red and rosé wines. Am. J. Enol. Vitic., 48, 357-363 